\title{
Article
}

\section{Graphene-coated hollow fiber membrane as the cathode in anaerobic electrochemical membrane bioreactors - Effect of configuration and applied voltage on performance and membrane fouling}

Craig Werner, Krishna Katuri, Hari Ananda Rao, Wei Chen, Zhiping Lai, Bruce E. Logan, Gary L. Amy, and Pascal E. Saikaly

Environ. Sci. Technol., Just Accepted Manuscript • DOI: 10.1021/acs.est.5b02833 • Publication Date (Web): 22 Dec 2015

Downloaded from http://pubs.acs.org on December 27, 2015

\section{Just Accepted}

"Just Accepted" manuscripts have been peer-reviewed and accepted for publication. They are posted online prior to technical editing, formatting for publication and author proofing. The American Chemical Society provides "Just Accepted" as a free service to the research community to expedite the dissemination of scientific material as soon as possible after acceptance. "Just Accepted" manuscripts appear in full in PDF format accompanied by an HTML abstract. "Just Accepted" manuscripts have been fully peer reviewed, but should not be considered the official version of record. They are accessible to all readers and citable by the Digital Object Identifier (DOI®). "Just Accepted" is an optional service offered to authors. Therefore, the "Just Accepted" Web site may not include all articles that will be published in the journal. After a manuscript is technically edited and formatted, it will be removed from the "Just Accepted" Web site and published as an ASAP article. Note that technical editing may introduce minor changes to the manuscript text and/or graphics which could affect content, and all legal disclaimers and ethical guidelines that apply to the journal pertain. ACS cannot be held responsible for errors or consequences arising from the use of information contained in these "Just Accepted" manuscripts. 
1 Graphene-coated hollow fiber membrane as the cathode in anaerobic electrochemical membrane bioreactors - Effect of configuration and applied voltage on performance and membrane fouling

Craig M. Werner ${ }^{a}{ }^{\S}$, Krishna P. Katuri ${ }^{a}{ }^{\S}$, Hari Ananda Rao ${ }^{a}$, Wei Chen ${ }^{b}$, Zhiping Lai ${ }^{b}$, Bruce E. Logan ${ }^{c}$, Gary L. Amy ${ }^{a}$ and Pascal E. Saikaly*a

${ }^{\mathrm{a}}$ King Abdullah University of Science and Technology, Biological and Environmental Sciences and Engineering Division, Water Desalination and Reuse Research Center, Thuwal 23955-6900, Saudi Arabia

${ }^{\mathrm{b}}$ King Abdullah University of Science and Technology, Advanced Membranes and Porous Materials Research Center, Thuwal 23955-6900, Kingdom of Saudi Arabia

${ }^{\mathrm{c}}$ Department of Civil and Environmental Engineering, Pennsylvania State University, University Park, PA 16802, USA

*Corresponding author: Phone:+966-5-44700129. E-mail: pascal.saikaly@kaust.edu.sa

${ }^{\S}$ These authors contributed equally to this work

Electrically conductive, graphene-coated hollow-fiber porous membranes were used as cathodes

in anaerobic electrochemical membrane bioreactors (AnEMBRs) operated at different applied voltages $(0.7 \mathrm{~V}$ and $0.9 \mathrm{~V})$ using a new rectangular reactor configuration, compared to a previous tubular design $(0.7 \mathrm{~V})$. The onset of biofouling was delayed and minimized in rectangular reactors operated at $0.9 \mathrm{~V}$, compared to those at $0.7 \mathrm{~V}$ due to higher rates of hydrogen production. Maximum transmembrane pressures for the rectangular reactor were only 0.10 bar $(0.7 \mathrm{~V})$ or 0.05 bar $(0.9 \mathrm{~V})$ after 56 days of operation, compared to 0.46 bar $(0.7 \mathrm{~V})$ for the tubular reactor after 52 days. The thickness of the membrane biofouling layer was approximately $0.4 \mu \mathrm{m}$ for rectangular reactors and $4 \mu \mathrm{m}$ for the tubular reactor. Higher permeate quality $(\mathrm{TSS}=$ $0.05 \mathrm{mg} / \mathrm{L})$ was achieved in the rectangular AnEMBR than the tubular AnEMBR (TSS $=17$ $\mathrm{mg} / \mathrm{L})$, likely due to higher current densities that minimized the accumulation of cells in 
31 suspension. These results show that the new rectangular reactor design, which had increased

32 rates of hydrogen production, successfully delayed the onset of cathode biofouling and improved 33 reactor performance.

34

35 TOC Art

36

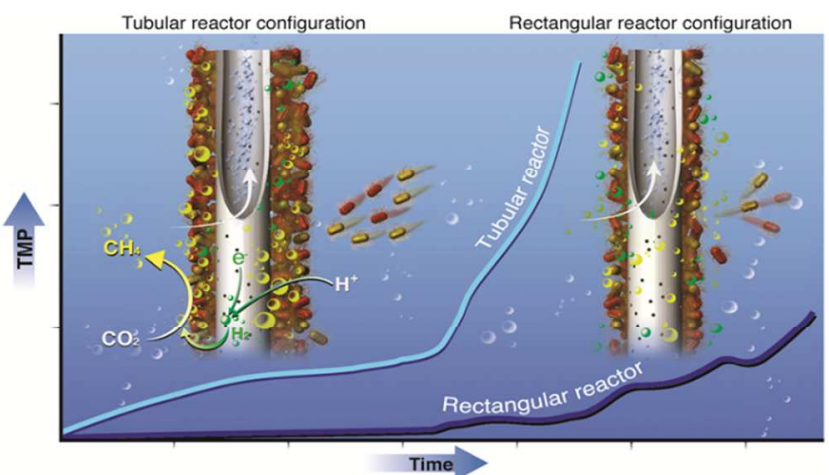

37 


\section{INTRODUCTION}

39 Wastewater treatment based on conventional activated sludge (CAS) processes consumes

40 relatively large amounts of energy $\left(\approx 0.6 \mathrm{kWh} / \mathrm{m}^{3}\right),{ }^{1}$ with about half of that energy used for

41 wastewater aeration. These systems also require large and efficient clarifiers to meet stringent

42 water quality standards for discharge. Aerobic membrane bioreactors (MBRs) have significantly

43 smaller footprints than CAS systems because they can achieve biological wastewater treatment

44 and solids separation in the same tank using a membrane to separate solids from treated water.

45 MBRs produce treated water of excellent quality suitable for reuse, but at a considerable energy

46 penalty $\left(1-2 \mathrm{kWh} / \mathrm{m}^{3}\right){ }^{2}$ A large fraction of the energy used to operate MBRs is due to aeration,

47 which is required to supply oxygen for bacterial respiration as well as to scour the membranes to

$48 \quad$ minimize fouling. ${ }^{3}$

Microbial electrochemical technologies (METs), such as microbial fuel cells (MFCs) and

50 microbial electrolysis cells (MECs), offer an alternative approach to effectively treat domestic

51 wastewater with recovery of the inherent energy as electricity (MFCs) ${ }^{4}$ or hydrogen (MECs). ${ }^{5}$

52 These systems use electroactive bacteria that oxidize organic matter in waste streams using an

53 electrode as the terminal electron acceptor. This electrode (anode) is electrically connected to a

54 cathode electrode where a reduction reaction occurs. By integrating MFCs or MECs with MBRs

55 it is possible to reclaim water for reuse purposes and significantly reduce energy consumption for

56 wastewater treatment. ${ }^{6-19}$ These systems are either truly integrated ${ }^{6,7,9,12-14,19}$ or the treatment

57 and water reclamation processes are separated within single-stage ${ }^{11,17,18}$ or two-stage systems ${ }^{8,}$

$5810,15,16$ (Table S1). In truly integrated systems the cathode served the dual function for filtration

59 and cathodic reaction. The advantage of using dual function cathodes is that it reduces cost and

60 footprint. However, the majority of the truly integrated systems incorporated electrically 
61 conductive flat-sheet membranes as the cathode, which lowers the specific surface area of the

62 cathode (i.e. cathode surface area per reactor volume). Katuri et al. recently developed a novel

63 tubular anaerobic electrochemical membrane bioreactor (AnEMBR) incorporating electrically

64 conductive nickel based hollow fiber membrane (Ni-HFM) as a cathode in a MEC reactor to

65 produce biogas at the cathode electrode surface. ${ }^{7}$ This cathode design increased the surface area

66 of the cathode per reactor volume, which is a critical aspect of the design of METs for practical

67 applications for wastewater treatment. ${ }^{7}$

68 Membrane fouling control is a considerable challenge in both aerobic and anaerobic

69 membrane-based bioreactors. ${ }^{15}$ The primary fouling control strategies for MFC-MBR systems

70 use aeration or granular activated carbon (GAC) (Table S1). However, neither approach can be

71 used in the AnEMBR system as it is a single-stage anaerobic system. An alternative suggested

72 for an MEC-based system was that increased hydrogen production rates might reduce membrane

73 fouling in the AnEMBR system due to the scouring effect of hydrogen gas bubbles on the

74 membrane surface. ${ }^{7}$ This alternative approach was based on an observation by Katuri et al.

75 where they increased the applied voltage from $0.5 \mathrm{~V}$ to $0.9 \mathrm{~V}$ in a tubular AnEMBR and

76 observed a significant drop in transmembrane pressure (TMP) at $0.9 \mathrm{~V}$ due to increased

77 hydrogen production rates. ${ }^{7}$ However, it was a one-time observation and their AnEMBR system

78 was designed only for "proof of concept" and thus was not optimized for performance. Several

79 factors including reactor configuration (e.g. specific cathode surface area and electrode spacing)

80 and operation (e.g. applied voltage) can affect hydrogen production rates ${ }^{20}$ and thus fouling

81 propensity in the AnEMBR system. Therefore, the objective of this study was to evaluate the

82 effect of reactor configuration (specific cathode surface area and electrode spacing) and applied

83 voltage on the performance of the AnEMBR system. 
To address this objective, two AnEMBR configurations (rectangular vs. tubular) were evaluated in terms of hydrogen production rates, electrochemical performance, membrane fouling propensity (biofilm formation and transmembrane pressure), and energy balances. Microscopic and next-generation sequencing techniques were used to characterize the biofouling layer on the cathode hollow fiber membranes (HFMs). The electrode spacing and specific cathode surface area was different in both configurations. For the rectangular configuration, the anode was placed directly opposite the vertically-aligned cathode HFMs to minimize electrode spacing $(\sim 1.5 \mathrm{~cm})$ and reduce ohmic (solution) resistance (Figure 1), whereas in the tubular AnEMBR the anode was placed below the complete cathode bundle with $\sim 2 \mathrm{~cm}$ between the bottom of the cathode bundle and the top of the anode. The specific surface area of the cathode for the rectangular reactor was $8.6 \mathrm{~m}^{2} / \mathrm{m}^{3}$, compared to $4 \mathrm{~m}^{2} / \mathrm{m}^{3}$ in the tubular AnEMBR. The cathode in both configurations was made of graphene HFMs (Gr-HFMs) fabricated using an earth abundant and inexpensive Ni skeleton as a support material in order to study the potential of hydrogen evolution by carbon-catalyzed cathodes as an alternative to metal-catalyzed cathodes in these type of systems. The key drivers to test graphene as the cathode catalyst in this study were sustainability and cost. Carbon based catalysts can be made sustainably and at a fraction of the cost of metal catalysts. To evaluate the effect of applied voltage, the rectangular AnEMBRs were operated at two different applied voltages $(0.7 \mathrm{~V}$ and $0.9 \mathrm{~V})$ commonly used in MEC studies ${ }^{21-23}$, whereas to evaluate the effect of electrode spacing and cathode specific area, the performance of the tubular AnEMBR operated at only $0.7 \mathrm{~V}$ was compared to the rectangular AnEMBR operated at the same applied voltage.

\section{MATERIALS AND METHODS}


Preparation of Cathodes. The porous Ni-HFM skeleton was fabricated using a combined

108

109

110

111

112

113

114

115

116

117

118

119

120

121

122

123

124

125

126

127 $128 \min$.

129

phase-inversion/sintering method as previously described. ${ }^{7}$ Graphene layers were synthesized directly on Ni-HFMs through a chemical vapor deposition (CVD) technique by exposing NiHFMs to a mixture of acetylene $(22 \mathrm{~mL} / \mathrm{min})$ and $\mathrm{H}_{2}(495 \mathrm{~mL} / \mathrm{min})$ gases at $1000^{\circ} \mathrm{C}$ for $5 \mathrm{~min}$, and then cooled in a tube furnace in argon gas.

Reactor Construction and Operation. A schematic representation of the rectangular AnEMBR configuration is shown in Figure 1; the design of the tubular AnEMBR was previously described. ${ }^{7}$ Four single chamber, rectangular AnEMBRs were constructed from plexiglass. A single tubular AnEMBR was constructed and operated in parallel in order to compare reactor performance and fouling propensity of the Gr-HFMs. The high reproducibility of duplicate tubular AnEMBRs was demonstrated previously. ${ }^{7}$ The rectangular AnEMBRs had a central housing $(14.5 \times 5 \times 5 \mathrm{~cm})$ and two solid end plates $(14.5 \times 5 \mathrm{~cm})$, with a final working liquid volume of $165 \mathrm{~mL}$, compared to $350 \mathrm{~mL}$ for the tubular AnEMBR. All chambers were sealed with silicon gaskets. The anode electrode of the rectangular AnEMBRs was prepared from nonwet proofed carbon cloth (CC-B1DBN40, Clean Fuel Cell Energy, USA) cut to fit on one side of the reactor (projected surface area of $35 \mathrm{~cm}^{2}$ ). The anode was held in position using a silicone adhesive spread around the edge of the reactor housing. The titanium foil $(2.5 \times 1.5 \times 0.1 \mathrm{~cm})$ current collector was positioned on one edge midway along the reactor housing. To ensure a good electrical connection, the area below the titanium current collector was not coated with silicone adhesive. The anode in the tubular AnEMBR was a graphite fiber brush $(10 \mathrm{~cm} \times 5 \mathrm{~cm}$, PANEX $33160 \mathrm{~K}$, ZOLTEK) containing a titanium core that was heat treated at $450^{\circ} \mathrm{C}$ for 15

Each reactor contained five Gr-HFMs bundled together using copper wire and conductive 
130 silver epoxy. The wire was fed through a port on the top of the reactor and connected to the 131 cathode bundle. Individual cathode fibers were $10 \mathrm{~cm}$ long with an outer diameter of $0.09 \mathrm{~cm}$

132 (projected surface area of $2.8 \mathrm{~cm}^{2}$ ). Each fiber was sealed at the bottom end with a small drop of 133 epoxy. Silicone tubing was placed over the top of the fibers up to the point of connection, and the 134 juncture was covered with epoxy to create a water tight membrane module and to seal the copper 135 wire from the solution. The ends of the fibers located within the silicone tubing were left open to 136 allow for filtration, and the tubes were connected to a peristaltic pump. The silicone tube at the 137 top of the cathode was fixed in place using epoxy glue. In the rectangular AnEMBR, the cathode 138 was placed $\sim 1.5 \mathrm{~cm}$ from the anode, whereas in the tubular AnEMBR the anode was placed 139 below the complete cathode bundle with $\sim 2 \mathrm{~cm}$ between the bottom of the cathode bundle and 140 the top of the anode.

141 A gas collection bag was connected to the top of the reactor using black tubing $(10 \mathrm{~cm})$ 142 connected through a $10 \mathrm{~mm}$ diameter threaded port on the top of the housing. A reference 143 electrode (Ag/AgCl, MF-2052, BASi) was placed between the anode and cathode in a vertical 144 orientation through a hole on the top of the housing to measure the anode potential. All 145 connections were sealed with non-conductive epoxy.

146 Duplicate rectangular AnEMBRs were started up at an applied voltage of $0.7 \mathrm{~V}$ or $0.9 \mathrm{~V}$ and 147 fed with $10 \mathrm{mM}$ acetate in a bicarbonate buffered medium containing (g/L): $\mathrm{NH}_{4} \mathrm{Cl}, 1.5$; $148 \mathrm{Na}_{2} \mathrm{HPO}_{4}, 0.6, \mathrm{KCl}, 0.1$ and 2.5, $\mathrm{Na}_{2} \mathrm{HCO}_{3}$; and trace minerals and vitamin solutions ( $\mathrm{pH}$ 7.0, 149 conductivity $=2.9 \mathrm{mS} / \mathrm{cm}) .^{7}$ Anaerobic digester sludge $(10 \% \mathrm{v} / \mathrm{v}$, Manfouha Wastewater 150 Treatment Plant, Riyadh, KSA) was used as the inoculum. After steady current production, the 151 acetate concentration was reduced to $5 \mathrm{mM}(320 \mathrm{mg} / \mathrm{L} \mathrm{COD})$ to provide a COD concentration 152 more representative of domestic wastewater. Voltage was applied using an external power source 
153 (3645A; Circuit Specialists, Inc., AZ), with the voltage monitored using a data logger (ADC 24, 154 PicoLog, UK) across an external resistor $\left(\mathrm{R}_{\mathrm{ex}} 10 \Omega\right)$. A tubular single AnEMBR $^{7}$ was started up 155 in the same manner at an applied voltage of $0.7 \mathrm{~V}$. All reactors were operated under fed-batch 156 conditions at room temperature $\left(25^{\circ} \mathrm{C}\right)$. Fresh medium was added at the end of each batch cycle, 157 when the current density dropped to within $10 \%$ of the peak current density [1 day $(0.9 \mathrm{~V}) ; 2$ 158 days $(0.7 \mathrm{~V}) ; 4$ days for the tubular design $(0.7 \mathrm{~V})$ ]. The rectangular AnEMBRs were operated 159 for a period of 72 days, whereas the experiments in the tubular AnEMBR were terminated on 160 day 52 due to severe cathode fouling.

161 The reactor medium was not filtered at the end of each batch cycle due to time constraints. 162 Instead, filtration was conducted at the end of alternate batch cycles or within at least two batch 163 cycles of the previous filtration event. The anolyte was filtered through the cathode using a 164 peristaltic pump (Masterfelx L/S, Cole-Parmer, Vernon Hills, IL.) at a permeate flux of 6.9 $165 \mathrm{~L} / \mathrm{m}^{2}-\mathrm{h}(\mathrm{LMH})$. The transmembrane pressure (TMP) of the membrane filters was measured using 166 a pressure transducer (68075-32, Cole-Parmer Instrument Company), and recorded using a data 167 acquisition system (LabVIEW, National Instruments) connected to a computer.

168 Membrane Chemical Cleaning. The rectangular AnEMBRs were disassembled on day 64 169 and the cathodes removed for cleaning. Each set of fibers was placed into a sodium hypochlorite 170 solution (1\%) for 15 minutes. The fibers were next immersed into concentrated hydrochloric acid $171 \mathrm{(HCl})$ for 5-10 s, before rinsing $(5-10 \mathrm{~s}$ at $40 \mathrm{KHz})$ in a beaker of deionized water in a sonication 172 bath (Branson, M1800, USA). The fibers were then dipped five times in the concentrated $\mathrm{HCl}$ 173 before being rinsed with distilled water and replaced into the reactor.

174 Analyses. Acetate and gas $\left(\mathrm{H}_{2}, \mathrm{~N}_{2}, \mathrm{CH}_{4}\right.$ and $\left.\mathrm{CO}_{2}\right)$ measurements were done at the end of 175 each batch cycle. Details on gas measurements, calculations of coulombic efficiency (CE) and 
176 internal resistance $\left(R_{\text {int }}\right)$, and analysis methods for linear sweep voltammetry (LSV), scanning

177 electron microscopy (SEM), and Raman spectroscopy are provided in the SI. All potentials are

178 reported versus $\mathrm{Ag} / \mathrm{AgCl}$.

179 To characterize the microbial communities, at the end of the experiment (i.e. day 72 for the 180 rectangular AnEMBRs and day 52 for the tubular AnEMBR), a small piece of a single fiber $(\sim 5$

$181 \mathrm{~mm}$ ) was cut for analyses. Genomic DNA was extracted using the PowerSoil TM DNA extraction

182 kit (MO BIO Laboratories Inc., USA) as per the manufacturer's instructions. The quality

183 (A260/A280) and quantity (A260) of the extracted genomic DNA was determined using a

184 NanoDrop 1000 spectrophotometer (Thermo Scientific, Waltham, MA). The bacterial and

185 archaeal community composition on the cathode was determined using 16S rRNA gene

186 pyrosequencing. Quantitative polymerase chain reaction (qPCR) was used to quantify the

187 abundance of total Bacteria and Archaea on the cathode. Details of qPCR and pyrosequencing 188 are presented in the Supporting Information.

\section{RESULTS AND DISCUSSION}

192 Characterization of the Cathodes. The Gr-HFM had an inner diameter of $\sim 750 \mu \mathrm{m}$ (Figure $1932 \mathrm{~A}$ ) and an average pore size of $1 \mu \mathrm{m}$ (Figure 2B). The graphene covering on Ni-HFM is evident 194 from the dark gray coloring with the characteristic wrinkled topography (Figure 2B) due to 195 variations in the thermal expansion coefficients of graphene and Ni during the cooling process of 196 CVD synthesis. ${ }^{24}$ The thickness of the graphene layer was $\sim 135 \mathrm{~nm}$ based on SEM of virgin Gr197 HFM (Figure S1). The microscale (laser spot size /'of $1.5 \mu \mathrm{m}$ ) Raman spectroscopic analysis of 198 the Gr-HFMs (Figure 2C) at random locations exhibited the characteristic $\mathrm{G}\left(1580 \mathrm{~cm}^{-1}\right)$ and 
199 symmetric $2 \mathrm{D}\left(2730 \mathrm{~cm}^{-1}\right)$ bands with the $2 \mathrm{D}$ to $\mathrm{G}$ band $\left(\mathrm{I}_{2 \mathrm{D}} / \mathrm{I}_{\mathrm{G}}\right)$ intensity ratio of 0.3 which 200 clearly indicated the formation of multi-layered graphene. The multi-layering of the graphene 201 can be distinguished by analysing the $\mathrm{I}_{2 \mathrm{D}} / \mathrm{I}_{\mathrm{G}}$ ratio of Raman spectra. $A \mathrm{I}_{2 \mathrm{D}} / \mathrm{I}_{\mathrm{G}}$ ratio of 2 with a 202 FWHM of $\sim 30 \mathrm{~cm}^{-1}$ (for $2 \mathrm{D}$ band) suggests a defect free single layer graphene. The $\mathrm{I}_{2 \mathrm{D}} / \mathrm{I}_{\mathrm{G}}$ ratio 203 decreases with increase in graphene layer thickness, due to variations in both $\mathrm{G}$ and $2 \mathrm{D}$ band 204 frequencies. ${ }^{25}$ The absence of a D band (at $1350 \mathrm{~cm}^{-1 \mathrm{f}}$ ) in the Raman spectrum signify that the 205 synthesized graphene layers on Ni-HFM skeleton were of high crystallinity, which is essential 206 for good electrical conductivity. The differences in Raman shifts between the Gr-HFM and Ni207 HFM skeleton clearly showed that the graphene layers completely covered the Ni surface during 208 the gaseous CVD process (Figure 2C). As a result, the characteristic peaks of Ni were not found 209 in the analysis of the Gr-HFM.

210 LSVs showed that Gr-HFM cathode had similar overpotentials compared to Ni-HFM $(\sim-0.5$ $211 \mathrm{~V})$, but both were more positive than stainless steel $(\sim-0.8 \mathrm{~V})$ or graphite cathode $(\sim-1.2 \mathrm{~V})$ 212 (Figure 2D). Gr-HFM had much better catalytic activity than SS and graphite with regards to the 213 onset of hydrogen evolution reaction (HER) potential. At $-1.0 \mathrm{~V}$, the maximum current density 214 of the Gr-HFM was only $20 \%$ that of the Ni-HFM (Figure 2D). The low Tafel slope $(0.100$ $215 \mathrm{~V} / \mathrm{dec})$ and large exchange current density of Ni-HFM $\left(0.002 \mathrm{~mA} / \mathrm{m}^{2}\right)$ compared to Gr-HFM $216\left(0.130 \mathrm{~V} / \mathrm{dec}\right.$ and $\left.0.00084 \mathrm{~mA} / \mathrm{m}^{2}\right)$ from the Tafel analysis (Figure $\left.\mathrm{S} 2\right)$ confirms the fact that $\mathrm{Ni}$ 217 is a better catalyst for HER than graphene even though both materials had the same onset 218 potential for HER.

219 Performance of AnEMBRs. Initial cycles following stable current production, up to day 30, 220 produced the highest hydrogen recoveries. After $\sim 50$ days of operation, prior to membrane 221 cleaning, methanogenesis was well established with little hydrogen gas recovery. The final stage 
222 up to $72 \mathrm{~d}$ shows performance for the rectangular AnEMBR following membrane cleaning on 223 day 64 . The slight drop in average current density observed at $40 \mathrm{~d}$ for reactors at $0.9 \mathrm{~V}$ was due 224 to experimental error during a filtration cycle that affected anode performance. The reactors 225 recovered within a few days to produce current densities similar to those measured before the 226 error.

227 The rectangular AnEMBRs produced an average current density of $29 \pm 2 \mathrm{~A} / \mathrm{m}^{3}(3.4 \pm 0.2$ $228 \mathrm{~A} / \mathrm{m}^{2}$; based on cathode surface area) at an applied voltage of $0.7 \mathrm{~V}$, and $49 \pm 5 \mathrm{~A} / \mathrm{m}^{3}(5.7 \pm 0.5$ $229 \mathrm{~A} / \mathrm{m}^{2}$ ) at $0.9 \mathrm{~V}$ over the first $50 \mathrm{~d}$ of operation (Figures $3 \mathrm{~A}$ and $\mathrm{B}$ ) compared to $10 \pm 1 \mathrm{~A} / \mathrm{m}^{3}(2.6$ $230 \pm 0.2 \mathrm{~A} / \mathrm{m}^{2}$ ) at $0.7 \mathrm{~V}$ in the tubular AnEMBR (Figure 3C). The volumetric current density of the 231 rectangular reactor at $0.7 \mathrm{~V}$ was nearly three times that of the tubular design, mainly due to 232 reduced electrode spacing and increased specific cathode surface area. ${ }^{26}$ The internal resistance 233 of the rectangular AnEMBR was $21.2 \pm 0.4 \Omega$ compared to $34.2 \pm 0.3 \Omega$ for the tubular AnEMBR. 234 The current density remained stable following chemical cleaning of the rectangular AnEMBR 235 after $64 \mathrm{~d}$ of operation (Figures $3 \mathrm{~A}$ and B) suggesting that the Gr-HFMs maintained their 236 integrity and catalytic activity after chemical treatment, and demonstrated the robustness of the 237 system.

238 Coulombic efficiency (CE) in the rectangular AnEMBRs was $>100 \%$ during the first $30 \mathrm{~d}$ of 239 operation at both applied voltages (Table 1). Coulombic efficiencies of $>100 \%$ have been 240 reported previously due to hydrogen recycling by exoelectrogens using hydrogen as the electron 241 donor. $^{27,28}$ However, when methanogenesis was observed in the system after $30 \mathrm{~d}$ of operation 242 (Figure 3) the CE was reduced to $<100 \%$, likely due to efficient conversion of hydrogen to 243 methane. The CEs decreased to $83 \%(0.7 \mathrm{~V})$ and $79 \%(0.9 \mathrm{~V})$ at $50 \mathrm{~d}$, but increased to $87 \%(0.7$ $244 \mathrm{~V})$ and $95 \%(0.9 \mathrm{~V})$ after $72 \mathrm{~d}$ of operation (Table 1). This increase in CE could be due to the 
245 cleaning of the membrane. After cleaning the cathode fibers of the rectangular reactors, the 246 hydrogen content of the biogas increased (Figures 3A and 3B) and possibly some hydrogen 247 recycling occurred resulting in increased CE. The CEs of the tubular reactor were always $<60 \%$. 248 Hydrogen production rates in the rectangular AnEMBRs were the highest for the six days 249 following stable current generation, and reached $0.21 \pm 0.05 \mathrm{~m}^{3} \mathrm{H}_{2} / \mathrm{m}^{3} \mathrm{~d}$ at $0.7 \mathrm{~V}$, and $0.41 \pm 0.08$ $250 \mathrm{~m}^{3} \mathrm{H}_{2} / \mathrm{m}^{3} \mathrm{~d}$ at $0.9 \mathrm{~V}$ at $30 \mathrm{~d}$ (Table 1). Hydrogen recoveries decreased with time to $0.02 \pm 0.03 \mathrm{~m}^{3}$ $251 \mathrm{H}_{2} / \mathrm{m}^{3} \mathrm{~d}(0.7 \mathrm{~V})$ and $0.28 \pm 0.15 \mathrm{~m}^{3} \mathrm{H}_{2} / \mathrm{m}^{3} \mathrm{~d}(0.9 \mathrm{~V})$ at $72 \mathrm{~d}$. Rates of hydrogen production for the 252 tubular AnEMBR were always very low, averaging $0.01 \pm 0.01 \mathrm{~m}^{3} \mathrm{H}_{2} / \mathrm{m}^{3} \mathrm{~d}$, likely due to the 253 longer cycles that allowed more time for hydrogen conversion to methane.

254 The cathodic recovery of biogas $\left(r_{\text {Cat }}\right)$ was highly variable in all tests. The highest recoveries 255 of 75 to $90 \%$ were obtained using an applied voltage of $0.9 \mathrm{~V}$ for the rectangular reactors with 256 the highest $\mathrm{H}_{2}$ production rates. Lower recoveries of 55 to $69 \%$ resulted for these reactors at 0.7 $257 \mathrm{~V}$, and recoveries of $38-57 \%$ were obtained for the tubular reactor with the lowest $\mathrm{H}_{2}$ production 258 rates (Table 1$)$.

Methane was detected at very low concentrations after $20 \mathrm{~d}(0.7 \mathrm{~V})$ and $23 \mathrm{~d}(0.9 \mathrm{~V})$, and 260 concentrations increased steadily with successive cycles. Methane generation increased more 261 rapidly at $0.7 \mathrm{~V}$ compared to $0.9 \mathrm{~V}$ (Figures $3 \mathrm{~A}$ and $3 \mathrm{~B}$ ) and it became the predominant gas after $26242 \mathrm{~d}$ of operation at $0.7 \mathrm{~V}$, except when the applied voltage was increased from $0.7 \mathrm{~V}$ to $0.9 \mathrm{~V}$ 263 (Figure 3A). In contrast, hydrogen was dominant in the biogas at $0.9 \mathrm{~V}$ for the duration of the 264 experiment (Figure 3B). The longer cycle time of approximately $2 \mathrm{~d}$ at $0.7 \mathrm{~V}$, compared to $1 \mathrm{~d}$ at $2650.9 \mathrm{~V}$, likely allowed for more time for conversion of $\mathrm{H}_{2}$ to methane. Methane generation was 266 well established after $15 \mathrm{~d}$ of operation in the tubular AnEMBR (Figure 3C). After cleaning the 267 cathode fibers of the rectangular reactors, the hydrogen content of the biogas increased (Figures 
$2683 \mathrm{~A}$ and $3 \mathrm{~B})$. However, methane generation was quickly re-established to previous levels within 269 2-3 d. It is likely that hydrogenotrophic methanogens on the walls of the reactor (as detected by 270 qPCR, data not shown) acted as an inoculum source for rapid establishment of hydrogenotrophic 271 methanogenesis on the membrane surface. The electron balances for the tubular AnEMBR and 272 rectangular AnEMBs revealed that a higher proportion of electrons were lost at the cathode to 273 other sinks (e.g. biomass, soluble microbial products) ${ }^{29}$ in reactors operated at $0.7 \mathrm{~V}$ versus those 274 operated at $0.9 \mathrm{~V}$ (Figures S3, S4 and S5).

The AnEMBRs showed a net positive energy gain over the course of the experiment except 276 for the tubular AnEMBR that showed a negative energy balance after $30 \mathrm{~d}$ of operation (Table 277 S5). After $50 \mathrm{~d}$ of operation, however, more energy was recovered as biogas than was supplied 278 as electricity in the tubular AnEMBR (Table S5). The composition of the recovered gas shifted 279 from predominantly hydrogen $(>80 \%)$ to a mixture of hydrogen and methane after $50 \mathrm{~d}$ of 280 operation of the rectangular AnEMBRs (Figures 3A and 3B). A gas comprised of a mixture of $281 \mathrm{H}_{2}$ and $\mathrm{CH}_{4}$ results in less energy due to the low conversion efficiencies of methane combustion. 282 For example, after $50 \mathrm{~d}$ the methane fraction of the biogas in the rectangular AnEMBRs was $28368 \%(0.7 \mathrm{~V})$ and $25 \%(0.9 \mathrm{~V})$ (Figure 3$)$ and the net process energy was negative (i.e. energy 284 demanding) (details provided in the energy balance section of SI). However, the energy required 285 to operate the AnEMBR at $0.7 \mathrm{~V}\left(0.19 \mathrm{kWh} / \mathrm{m}^{3}\right)$ and $0.9 \mathrm{~V}\left(0.13 \mathrm{kWh} / \mathrm{m}^{3}\right)$ after deducting the 286 maximum electrical energy that could be recovered are still much lower than what is required for 287 large-scale aerobic MBRs $\left(1-2 \mathrm{kWh} / \mathrm{m}^{3}\right) .^{2}$

288 Analysis of Microbial Communities. Generation of methane is well documented in single289 chamber MEC systems, ${ }^{22}$ but the microbial community on methane-producing biocathode is less 290 well studied. Analysis of archaeal 16S rRNA gene pyrosequencing data revealed that 
291 hydrogenotrophic methanogens belonging to the genus Methanobrevibacter (family

292 Methanobacteriaceae) were the dominant methanogens (89\%-99\%) in the rectangular

293 AnEMBRs regardless of the applied voltage tested. Two previous studies reported a

294 predominance of members of the family Methanobacteriaceae on MEC cathodes. ${ }^{30,31}$

295 Hydrogenotrophic methanogens belonging to the genus Methanobrevibacter (27\%), and

296 Methanobacterium (30\%), were the dominant methanogens in the tubular AnEMBR (Figure 4,

297 Table S3). In addition, members of unclassified Methanobacteriaceae (43\%) were detected on

298 the cathode of the tubular AnEMBR (Figure 4). The difference in the methanogenic community

299 composition between the tubular and rectangular AnEMBR could be due to differences in the

300 rates of hydrogen production. Acetoclastic methanogens were not detected in any of the

301 AnEMBRs, based on 16S rRNA gene pyrosequencing, despite the use of acetate as a fuel.

302 Pyrosequencing analysis of bacterial 16S rRNA gene revealed that members of the genus

303 Desulfovibrio were the dominant bacterial communities $(24 \%-50 \%)$ on the cathodes of the

304 rectangular AnEMBRs at both applied voltages (Figure 4, Table S4). Members of the genus

305 Desulfovibrio are sulfate-reducing bacteria and it has been reported that under electron acceptor

306 limited conditions several members of Desulfovibrio are able to catalyze hydrogen production at

307 low cathode potentials $\leq-0.44 \mathrm{~V}$ vs SHE using the cathode as the sole source of electrons and

308 energy. ${ }^{31-33}$ Therefore, it is possible that members of the genus Desulfovibrio were selectively

309 enriched on the Gr-HFMs due to the low cathode potentials $(-0.89 \mathrm{~V}$ vs SHE at $0.7 \mathrm{~V}$ and -0.99

$310 \mathrm{~V}$ vs SHE at $0.9 \mathrm{~V}$ ) and electron donor availability. Also, Desulfovibrio sp. might have

311 contributed to bioelectrochemical methane production in the AnEMBR system through

312 production of hydrogen, which was then consumed by hydrogenotrophic methanogens. ${ }^{30}$ 
Fouling of AnEMBR. Filtration and TMP measurements were started after $24 \mathrm{~d}$ of operation

314 for the rectangular AnEMBRs, and $15 \mathrm{~d}$ for the tubular AnEMBR. Rectangular AnEMBRs

315 operated at $0.9 \mathrm{~V}$ showed lower TMPs than those operated at $0.7 \mathrm{~V}$ over the course of the

316 experiment (Figures 3A and B). From day 24 to 40 the TMP for reactors at $0.9 \mathrm{~V}$ was

317 approximately half that of reactors at $0.7 \mathrm{~V}$, with a TMP of 0.05 bar at $72 \mathrm{~d}$ at $0.9 \mathrm{~V}$, compared

318 to 0.10 bar at $0.7 \mathrm{~V}$. This reduction in cathode fouling at $0.9 \mathrm{~V}$ was likely a result of the greater

319 hydrogen production rates of this reactor. We hypothesize that biofouling and TMP in the

320 AnEMBR are directly related to rates of reactions. Data from this study shows a correlation

321 between current density, hydrogen production rates and TMP (Figure S6). Since the hydrogen

322 evolution rate at the cathode membrane surface is directly proportional to the current density,

323 any change in the configuration, such as increasing the specific cathode surface area and

324 reducing electrode spacing, that increases the current density should lead to reduced fouling and

325 lower TMP.

326 Katuri et al. similarly observed a noticeable drop in TMP in a tubular AnEMBR after

327 increasing the applied voltage from $0.5 \mathrm{~V}$ to $0.9 \mathrm{~V} .^{7}$ It was suggested that this reduction in TMP

328 was due to the scouring effect of the increased rate of hydrogen bubble formation at the

329 membrane surface. However, increasing the applied voltage from $0.7 \mathrm{~V}$ to $0.9 \mathrm{~V}$ on day 59 (after

330 the cathode had already developed a higher TMP) did not reduce the TMP (Figure 3A). The

331 biofouling layer that had developed on these cathodes $(0.4-0.5 \mu \mathrm{m})$ (Figures 5A and 5B) likely

332 limited the effectiveness of this approach. The biofilm was significantly thicker $(4 \mu \mathrm{m})$ in the

333 report by Katuri et al. ${ }^{7}$ and scouring a biofilm of such a thickness would result in a more

334 noticeable drop in the TMP. 
After chemically cleaning the membranes (day 64), the TMP decreased significantly to 0.05 bar for the rectangular reactor at $0.7 \mathrm{~V}$, and 0.02 bar at $0.9 \mathrm{~V}$. After further operation for $8 \mathrm{~d}$, the TMP of reactors at $0.7 \mathrm{~V}$ increased to 0.13 bar, compared to 0.06 bar for reactors at $0.9 \mathrm{~V}$ (Figures 3A and 3B). Although the TMP increased again with time, the final TMP values (72 days of operation) were $72 \%(0.7 \mathrm{~V})$ and $87 \%(0.9 \mathrm{~V})$ lower than the TMP of the tubular design ( 0.46 bar, $50 \mathrm{~d}$ of operation). These results indicate that the rectangular configuration reduced biofouling resulting in a lower TMP (Figure 3). It should be noted that chemical cleaning of the Gr-HFM did not result in any structural changes of the graphene layers as revealed by Raman analysis (data not shown). Graphene adheres strongly to a metal support such as nickel due to strong bonding with the metal lattice that occurs during the preparation process. ${ }^{24,34}$ Therefore it is unlikely to be damaged easily or separate from the nickel support unless the graphene corrodes. However, corrosion is unlikely since the cathode potential in these systems is lower than the equilibrium potential for carbon oxidation ( $>1.2 \mathrm{~V}$ vs NHE). In addition, graphene has been shown to be very resistant to corrosion under both acidic and basic conditions. ${ }^{35}$

SEM images indicated that the membrane fouling layer from reactors of the rectangular design were relatively flat and thin after 64 days of operation (Figures 5A and 5B). The fouling layer showed an irregular scattering of cells and a glue-like coating, presumed to be extracellular polymeric substances (EPS). ${ }^{36}$ There were no clear differences in the morphologies or coverages of the fouling layer that might explain the differences in TMPs. However, the morphology of the fouling layer that developed after cleaning was different for reactors at $0.7 \mathrm{~V}$ and $0.9 \mathrm{~V}$ (Figures 5C and 5D). The fouling layer at $0.7 \mathrm{~V}$ reactors appeared to contain larger quantities of EPS whereas the fouling layer at $0.9 \mathrm{~V}$ appeared more sponge-like with less EPS (Figures 5C and 5D). More open pores were visible in the membranes from reactors at $0.9 \mathrm{~V}$ compared to 
358

359

360

361

362

363

364

365

366

367

368

369

370

371

372

373

374

375

376

377

378

379

380

membranes from reactors at $0.7 \mathrm{~V}$. The presence of more open pores could explain the lower TMP measured for reactors at $0.9 \mathrm{~V}$ after $72 \mathrm{~d}$ of operation. The formation of hydrogen contributed to the formation of pores in the membrane fouling layer and these pores may have affected the morphology of this layer.

The fouling layers were approximately $0.4-0.5 \mu \mathrm{m}$ thick in the rectangular AnEMBRs (Figures 5A-D). This is approximately one tenth the thickness of the fouling layer observed on the cathode membranes of the tubular AnEMBR design $(\sim 4 \mu \mathrm{m})$ (Figures 5E and 5F). Also, the biofouling layer of cathode from the tubular reactor showed higher abundance of prokaryotes (bacteria and archaea), expressed as copies/ng DNA, compared to the rectangular reactors (Figure S7). These support other evidence that improving the reactor performance, in terms of current densities, improved the hydrogen production rates, resulting in reduced fouling. In addition to the in situ cleaning effect due to hydrogen bubble formation at the membrane surface, other factors such as the low cathode potential ${ }^{37}$, the localized high $\mathrm{pH}$ at the cathode surface due to proton consumption ${ }^{37}$ and the electrostatic repulsion of negatively charged foulants away from the negatively charged cathode membrane surface ${ }^{12,13,38}$ may have collectively contributed to fouling control in the AnEMBR system.

Both pyrosequencing and qPCR of $16 \mathrm{~S}$ rRNA gene revealed that members of the domain Bacteria and Archaea contributed to biofouling in the tubular and the rectangular AnEMBRs (Figures 4 and S7). However, the composition and abundance of the two domains varied according to applied voltage and reactor configuration (Figures 4 and S7). Also, the abundance of methanogenic archaea on the cathodes of the rectangular reactors were significantly lower compared to the tubular reactor (Figure S7). This noticeable difference in abundance is also due to the rates of hydrogen production. Due to the low solubility $(0.74 \mu \mathrm{M})^{39}$ and density 
$381(0.0000089 \mathrm{~g} / \mathrm{mL})$ of $\mathrm{H}_{2}$, the hydrogenotrophic methanogens on the cathode of the rectangular

382

383

384

385

386

387

388

389

390

391

392

393

394

395

396

397

398

399

400

401

402

reactor were not capable of consuming the $\mathrm{H}_{2}$ as fast as its rate of generation on the membrane

surface. This phenomenon resulted in lower abundance of hydrogenotrophic methanogens in the rectangular reactor compared to the tubular reactor (Figure S7). The opposite is true for the tubular configuration, as hydrogenotrophic methanogens were capable of consuming the $\mathrm{H}_{2}$ generated on the cathode due to lower rates of hydrogen production compared to the rectangular reactors.

Permeate Water Quality. Acetate removal in the rectangular AnEMBRs after $72 \mathrm{~d}$ of operation was $>83 \%$ at both applied voltages compared to $>99 \%$ in the tubular AnEMBR. The higher acetate removal in the tubular AnEMBR was likely due to the longer cycle time (4 days compared to 1 or 2 days for the other reactors). It is known that higher current densities result in faster COD removal rate, ${ }^{20}$ and hence a shorter cycle time is required to remove COD. The TSS in the permeate was very low in the rectangular AnEMBRs $(0.05 \mathrm{mg} / \mathrm{L})$. However, the TSS was $17 \mathrm{mg} / \mathrm{L}$ in the tubular AnEMBR effluent despite similar pore size $(\sim 1 \mu \mathrm{m})$. The lower TSS may be due to higher current densities that resulted in faster acetate removal rates at the anode ${ }^{40}$ for electricity generation $(\mathrm{CE}=85 \%)$ and shorter cycle time and may have minimized the accumulation of cells in suspension. Improvements in membrane fabrication to reduce the pore size $(<0.1 \mu \mathrm{m})$ would help to improve permeate water quality. ${ }^{6}$

In conclusion, the graphene layer on the cathode served as both a catalyst for HER and as a separate membrane for filtration. The improved performance of the graphene coated cathodes demonstrated that graphene-catalyzed cathodes could be a feasible alternative to traditional 
403 metal-catalyzed cathodes. Graphene is particularly attractive as an electrode material as its

404 specific surface area is at least 1000 fold higher than conventional carbon-based materials. ${ }^{41}$

405 Membrane cleaning or replacement is a significant operational expense in aerobic and

406 anaerobic MBRs and poses a constant challenge. ${ }^{42}$ Here we demonstrated that modifications in

407 reactor configuration improved the rates of hydrogen evolution and hence in-situ cleaning of the

408 membranes, which enabled operation of the rectangular AnEMBRs for two months without

409 replacement or cleaning (e.g. backwashing or chemical treatment) of the membranes.

410 Although energy-neutrality was not achieved in our system, the energy balance values for the

411 AnEMBRs were much lower than those required for large-scale aerobic MBRs.

412 Hydrogenotrophic methanogenesis is unavoidable in single chamber MECs and presents an

413 alternative direction for the development of AnEMBRs. Understanding the ecophysiology of

414 methane producing biocathodes in AnEMBRs and how it can be tailored to maximize methane

415 production would be beneficial to achieve energy-neutral AnEMBR system.

416 The results obtained here were only for an acetate-based medium, and thus the performance

417 with actual domestic wastewaters still needs to be investigated. Future studies that test the

418 performance of AnEMBRs with real domestic wastewater are needed to further develop this

419 technology and move it towards implementation.

420

421 AUTHOR INFORMATION

422 Corresponding Author

423 *Phone: +966-5-44700129. E-mail: pascal.saikaly@kaust.edu.sa. 
426 This work was supported by Center Competitive Funding Program (FCC/1/1971-05-01) to P.S.

427 and a PhD fellowship award (C.W.) from the King Abdullah University of Science and

428 Technology (KAUST).

429

430 ASSOCIATED CONTENT

431 Supporting Information Available

432 Supporting information includes: Summary table of studies on integrating MET with membrane

433 filtration processes, details on chemical, electrochemical, SEM, Raman spectroscopy, qPCR and

434 pyrosequencing analysis, energy calculations, SEM-EDX analysis of virgin Gr-HFM, Tafel plot,

435 and electron balance. This information is available free of charge via the Internet at

436 http://pubs.acs.org/. 


\section{REFERENCES}

1. McCarty, P. L.; Bae, J.; Kim, J., Domestic wastewater treatment as a net energy producer-Can this be achieved? Environ. Sci. Technol. 2011, 45, (17), 7100-7106.

2. Cornel, P.; Krause, S., State of the art on MBR in Europe. Technical Note of National Institute for Land and Infrastructure Management 2004, 186, 151-162.

3. Judd, S., The MBR Book: Principles and Applications of Membrane Bioreactors for Water and Wastewater Treatment. Elsevier: 2010.

4. Ahn, Y.; Logan, B., Domestic wastewater treatment using multi-electrode continuous flow MFCs with a separator electrode assembly design. Appl. Microbiol. Biotechnol. 2013, 97, (1), 409-416.

5. Escapa, A.; San Martin, M. I.; Moran, A., Potential use of microbial electrolyis cells (MECs) in domestic wastewater treatment plants for energy recovery. Front. Energy Res. 2014, $2,1-10$.

6. Malaeb, L.; Katuri, K. P.; Logan, B. E.; Maab, H.; Nunes, S. P.; Saikaly, P. E., A hybrid microbial fuel cell membrane bioreactor with a conductive ultrafiltration membrane biocathode for wastewater treatment. Environ. Sci. Technol. 2013, 47, (20), 11821-11828.

7. $\quad$ Katuri, K. P.; Werner, C. M.; Jimenez-Sandoval, R. J.; Chen, W.; Jeon, S.; Logan, B. E.; Lai, Z.; Amy, G. L.; Saikaly, P. E., A novel anaerobic electrochemical membrane bioreactor (AnEMBR) with conductive hollow-fiber membrane for treatment of low-organic strength solutions. Environ. Sci. Technol. 2014, 48, (21), 12833-12841.

8. Ren, L.; Ahn, Y.; Logan, B. E., A two-stage microbial fuel cell and anaerobic fluidized bed membrane bioreactor (MFC-AFMBR) system for effective domestic wastewater treatment. Environ. Sci. Technol. 2014, 48, (7), 4199-4206.

9. Wang, Y.-K.; Sheng, G.-P.; Li, W.-W.; Huang, Y.-X.; Yu, Y.-Y.; Zeng, R. J.; Yu, H.-Q., Development of a novel bioelectrochemical membrane reactor for wastewater treatment. Environ. Sci. Technol. 2011, 45, (21), 9256-9261.

10. Wang, Y.-P.; Liu, X.-W.; Li, W.-W.; Li, F.; Wang, Y.-K.; Sheng, G.-P.; Zeng, R. J.; Yu, H.-Q., A microbial fuel cell-membrane bioreactor integrated system for cost-effective wastewater treatment. Appl. Energy 2012, 98, 230-235.

11. Wang, Y.-K.; Sheng, G.-P.; Shi, B.-J.; Li, W.-W.; Yu, H.-Q., A novel electrochemical membrane bioreactor as a potential net energy producer for sustainable wastewater treatment. Sci. Rep. 2013, 3, (1864), 1-6.

12. Liu, J.; Liu, L.; Gao, B.; Yang, F.; Crittenden, J.; Ren, N., Integration of microbial fuel cell with independent membrane cathode bioreactor for power generation, membrane fouling mitigation and wastewater treatment. Int. J. Hydrogen Energy 2014, 39, (31), 17865-17872.

13. Song, J.; Liu, L.; Yang, F.; Ren, N.; Crittenden, J., Enhanced electricity generation by triclosan and iron anodes in the three-chambered membrane bio-chemical reactor (TC-MBCR). Bioresour. Technol. 2013, 147, 409-415.

14. Li, J.; Ge, Z.; He, Z., A fluidized bed membrane bioelectrochemical reactor for energyefficient wastewater treatment. Bioresour. Technol. 2014, 167, (0), 310-315.

15. Tian, Y.; Ji, C.; Wang, K.; Le-Clech, P., Assessment of an anaerobic membrane bioelectrochemical reactor (AnMBER) for wastewater treatment and energy recovery. J. Membr. Sci. 2014, 450, 242-248. 
16. Li, J.; Ge, Z.; He, Z., Advancing membrane bioelectrochemical reactor (MBER) with hollow-fiber membranes installed in the cathode compartment. J. Chem. Technol. Biotechnol. 2013, 89, (9), 1330-1336.

17. Ge, Z.; Ping, Q.; He, Z., Hollow-fiber membrane bioelectrochemical reactor for domestic wastewater treatment. J. Chem. Technol. Biotechnol. 2013, 88, (8), 1584-1590.

18. Li, Y.; Liu, L.; Liu, J.; Yang, F.; Ren, N., PPy/AQS (9, 10-anthraquinone-2-sulfonic acid) and PPy/ARS (Alizarin Red's) modified stainless steel mesh as cathode membrane in an integrated MBR/MFC system. Desalination 2014, 349, (0), 94-101.

19. Wang, Z.; Huang, J.; Zhu, C.; Ma, J.; Wu, Z., A bioelectrochemically-assisted membrane bioreactor for simultaneous wastewater treatment and energy production. Chem. Eng. and Technol. 2013, 36, (12), 2044-2050.

20. Sleutels, T. H. J. A.; Ter Heijne, A.; Buisman, C. J. N.; Hamelers, H. V. M., Bioelectrochemical Systems: An Outlook for Practical Applications. ChemSusChem 2012, 5, (6), 1012-1019.

21. Ambler, J. R.; Logan, B. E., Evaluation of stainless steel cathodes and a bicarbonate buffer for hydrogen production in microbial electrolysis cells using a new method for measuring gas production. Int. J. Hydrogen Energy 2011, 36, (1), 160-166.

22. Call, D.; Logan, B. E., Hydrogen production in a single chamber microbial electrolysis cell lacking a membrane. Environ. Sci. Technol. 2008, 42, (9), 3401-3406.

23. Sleutels, T. H.; Heijne, A. T.; Buisman, C. J.; Hamelers, H. V., Steady-state performance and chemical efficiency of Microbial Electrolysis Cells. Int. J. Hydrogen Energy 2013, 38, (18), 7201-7208.

24. Huang, L.; Chang, Q.; Guo, G.; Liu, Y.; Xie, Y.; Wang, T.; Ling, B.; Yang, H., Synthesis of high-quality graphene films on nickel foils by rapid thermal chemical vapor deposition. Carbon 2012, 50, (2), 551-556.

25. Ferrari, A. C.; Basko, D. M., Raman spectroscopy as a versatile tool for studying the properties of graphene. Nat. Nano. 2013, 8, (4), 235-246.

26. Logan, B. E., Essential Data and Techniques for Conducting Microbial Fuel Cell and other Types of Bioelectrochemical System Experiments. ChemSusChem 2012, 5, (6), 988-994. 27. Call, D.; Wagner, R.; Logan, B., Hydrogen production by Geobacter species and a mixed consortium in a microbial electrolysis cell. Applied and Environmental Microbiology 2009, 75, (24), 7579.

28. Lu, L.; Xing, D.; Xie, T.; Ren, N.; Logan, B. E., Hydrogen production from proteins via electrohydrogenesis in microbial electrolysis cells. Biosens. Bioelectron. 2010, 25, (12), 26902695.

29. Lee, H.-S.; Parameswaran, P.; Kato-Marcus, A.; Torres, C. I.; Rittmann, B. E., Evaluation of energy-conversion efficiencies in microbial fuel cells (MFCs) utilizing fermentable and non-fermentable substrates. Water Research 2008, 42, (6), 1501-1510.

30. Siegert, M.; Li, X.-F.; Yates, M. D.; Logan, B. E., The presence of hydrogenotrophic methanogens in the inoculum improves methane gas production in microbial electrolysis cells. Front. Microbiol. 2015, 5, 778.

31. Van Eerten-Jansen, M. C.; Veldhoen, A. B.; Plugge, C. M.; Stams, A. J.; Buisman, C. J.; Ter Heijne, A., Microbial community analysis of a methane-producing biocathode in a bioelectrochemical system. Archaea 2013, 2013. 
525 32. Aulenta, F.; Catapano, L.; Snip, L.; Villano, M.; Majone, M., Linking Bacterial 526 Metabolism to Graphite Cathodes: Electrochemical Insights into the H2-Producing Capability of 527 Desulfovibrio sp. ChemSusChem 2012, 5, 1080-1085.

528 33. Croese, E.; Pereira, M.; Euverink, G.-J.; Stams, A.; Geelhoed, J., Analysis of the 529 microbial community of the biocathode of a hydrogen-producing microbial electrolysis cell. 530 Appl. Microbiol. Biotechnol. 2011, 92, (5), 1083-1093.

531 34. Beesley, D. J.; Semple, J.; Jagadamma, L. K.; Amassian, A.; McLachlan, M. A.; 532 Anthopoulos, T. D., Sub-15-nm patterning of asymmetric metal electrodes and devices by 533 adhesion lithography. Nat. Commun. 2014, 5.

534 35. Mogera, U.; Kurra, N.; Radhakrishnan, D.; Narayana, C.; Kulkarni, G. U., Low cost, 535 rapid synthesis of graphene on $\mathrm{Ni}$ : An efficient barrier for corrosion and thermal oxidation.

536 Carbon 2014, 78, 384-391.

537 36. De Beer, D.; Stoodley, P., Microbial Biofilms. In The Prokaryotes, Dworkin, M.;

538 Falkow, S.; Rosenberg, E.; Schleifer, K.-H.; Stackebrandt, E., Eds. Springer New York: 2006; pp 539 904-937.

$540 \quad 37 . \quad$ Logan, B. E.; Call, D.; Cheng, S.; Hamelers, H. V. M.; Sleutels, T. H. J. A.; Jeremiasse, 541 A. W.; Rozendal, R. A., Microbial electrolysis cells for high yield hydrogen gas production from 542 organic matter. Environ. Sci. Technol. 2008, 42, (23), 8630-8640.

543 38. Liu, J.; Liu, L.; Gao, B.; Yang, F., Integration of bio-electrochemical cell in membrane 544 bioreactor for membrane cathode fouling reduction through electricity generation. J. Membr. Sci. 545 2013, 430, 196-202.

546 39. Sonne-Hansen, J.; Westermann, P.; Ahring, B. K., Kinetics of sulfate and hydrogen 547 548 549 550 551

552

553

554 uptake by the thermophilic sulfate-reducing bacteria Thermodesulfobacterium sp. strain JSP and Thermodesulfovibrio sp. strain R1Ha3. Appl. Environ. Microbiol. 1999, 65, (3), 1304-1307. 40. Ren, L.; Zhang, X.; He, W.; Logan, B. E., High current densities enable exoelectrogens to outcompete aerobic heterotrophs for substrate. Biotechnol. Bioeng. 2014, 111, (11), 2163-2169.

41. Gadhamshetty, V.; Koratkar, N., Nano-engineered biocatalyst-electrode structures for next generation microbial fuel cells. Nano Energy 2012, 1, (1), 3-5.

42. Le-Clech, P.; Chen, V.; Fane, T. A. G., Fouling in membrane bioreactors used in wastewater treatment. J. Membr. Sci. 2006, 284, (1-2), 17-53. 


\section{FIGURE CAPTIONS}

Figure 1. Schematic diagram of the rectangular AnEMBR used in this study. (1) Gr-HFM bundle, (2) bioanode, (3) power source, (4) external resistor, (5) gas bag, (6) pressure sensor, (7) pump and (8) permeate. Bubbles represent different gases: $\mathrm{CO}_{2}$ (light blue), $\mathrm{H}_{2}$ (green) and $\mathrm{CH}_{4}$ (yellow).

Figure 2. Scanning electron micrographs of Gr-HFM (A and B), Raman spectra of Gr-HFM and Ni-HFM (C) and linear sweep voltammetry (D).

Figure 3. Peak volumetric current densities, TMP and gas composition for rectangular AnEMBRs operated at (A) $0.7 \mathrm{~V}$, (B) $0.9 \mathrm{~V}$ and (C) the tubular AnEMBR operated at $0.7 \mathrm{~V}$. Values represent averages of duplicate reactors. Section highlighted with gray color (A) indicates cycles at which $0.7 \mathrm{~V}$ reactors were switched to $0.9 \mathrm{~V}$ (day 59 to 63). Gray arrows represent the time at which the Gr-HFMs were sampled for SEM imaging and black arrows represent the time when biomass samples were collected for microbial community analysis.

Figure 4. Pyrosequencing results of the bacterial and archaeal community on the cathode from the rectangular and tubular configuration. Samples from the tubular AnEMBR failed to amplify with bacterial primers. The asterisk denotes the results for the tubular configuration. Class: $\mathrm{C}$; Order: O; Family: F; Genus: G. Taxa that represent less than 1\% of the total bacterial community composition were classified as "others".

Figure 5. Scanning electron micrographs of Gr-HFMs after $64 \mathrm{~d}(\mathrm{~A}-0.7 \mathrm{~V}$ and $\mathrm{B}-0.9 \mathrm{~V})$ and $72 \mathrm{~d}(\mathrm{C}-0.7 \mathrm{~V}, \mathrm{D}-0.9 \mathrm{~V})$ of operation. Also shown are SEM images of Gr-HFMs from the tubular reactor after $52 \mathrm{~d}$ of operation at $0.7 \mathrm{~V}(\mathrm{E}$ and $\mathrm{F})$. 
Table 1. Performance of the rectangular AnEMBRs acclimated at different applied voltages and the tubular AnEMBR operated at $0.7 \mathrm{~V}$

587

\begin{tabular}{|c|c|c|c|c|c|}
\hline \multicolumn{6}{|l|}{$0.7 \mathrm{~V}$} \\
\hline $\begin{array}{l}\text { Experimental } \\
\text { stage }\end{array}$ & $\begin{array}{l}\text { Acetate } \\
\text { removed } \\
(\%)\end{array}$ & CE (\%) & $\begin{array}{l}\mathrm{Q}_{\mathrm{H} 2} \\
\left(\mathrm{~m}^{3} / \mathrm{m}^{3} / \mathrm{d}\right)\end{array}$ & $\begin{array}{l}\mathrm{Q}_{\mathrm{CH} 4} \\
\left(\mathrm{~m}^{3} / \mathrm{m}^{3} / \mathrm{d}\right)\end{array}$ & $\begin{array}{l}r_{\text {Cat }} \% \\
\text { (biogas) }\end{array}$ \\
\hline $30 \mathrm{~d}$ & $83.4 \pm 4.1$ & $104 \pm 16$ & $0.21 \pm 0.05$ & $0.01 \pm 0.01$ & $69 \pm 13$ \\
\hline $50 \mathrm{~d}$ & $89.5 \pm 2.9$ & $83 \pm 21$ & $0.07 \pm 0.06$ & $0.04 \pm 0.02$ & $60 \pm 9$ \\
\hline $72 \mathrm{~d}$ & $85.0 \pm 11.3$ & $87.2 \pm 6$ & $0.02 \pm 0.03$ & $0.04 \pm 0.03$ & $55 \pm 34$ \\
\hline \multicolumn{6}{|l|}{$0.9 \mathrm{~V}$} \\
\hline $30 \mathrm{~d}$ & $62.1 \pm 3.6$ & $114 \pm 20$ & $0.42 \pm 0.08$ & $0.01 \pm 0.004$ & $76 \pm 10$ \\
\hline $50 \mathrm{~d}$ & $83.4 \pm 7.7$ & $79 \pm 30$ & $0.17 \pm 0.08$ & $0.07 \pm 0.028$ & $75 \pm 14$ \\
\hline $72 \mathrm{~d}$ & $83.3 \pm 3.7$ & $95 \pm 2$ & $0.28 \pm 0.15$ & $0.09 \pm 0.033$ & $90 \pm 29$ \\
\hline \multicolumn{6}{|l|}{ Tubular $0.7 \mathrm{~V}$} \\
\hline $30 \mathrm{~d}$ & $99.9 \pm 0.04$ & $63 \pm 21$ & $0.01 \pm 0.01$ & $0.01 \pm 0.001$ & $38 \pm 18$ \\
\hline $50 \mathrm{~d}$ & $99.7 \pm 0.5$ & $57 \pm 7$ & $0.001 \pm 0.001$ & $0.02 \pm 0.004$ & $57 \pm 8$ \\
\hline
\end{tabular}




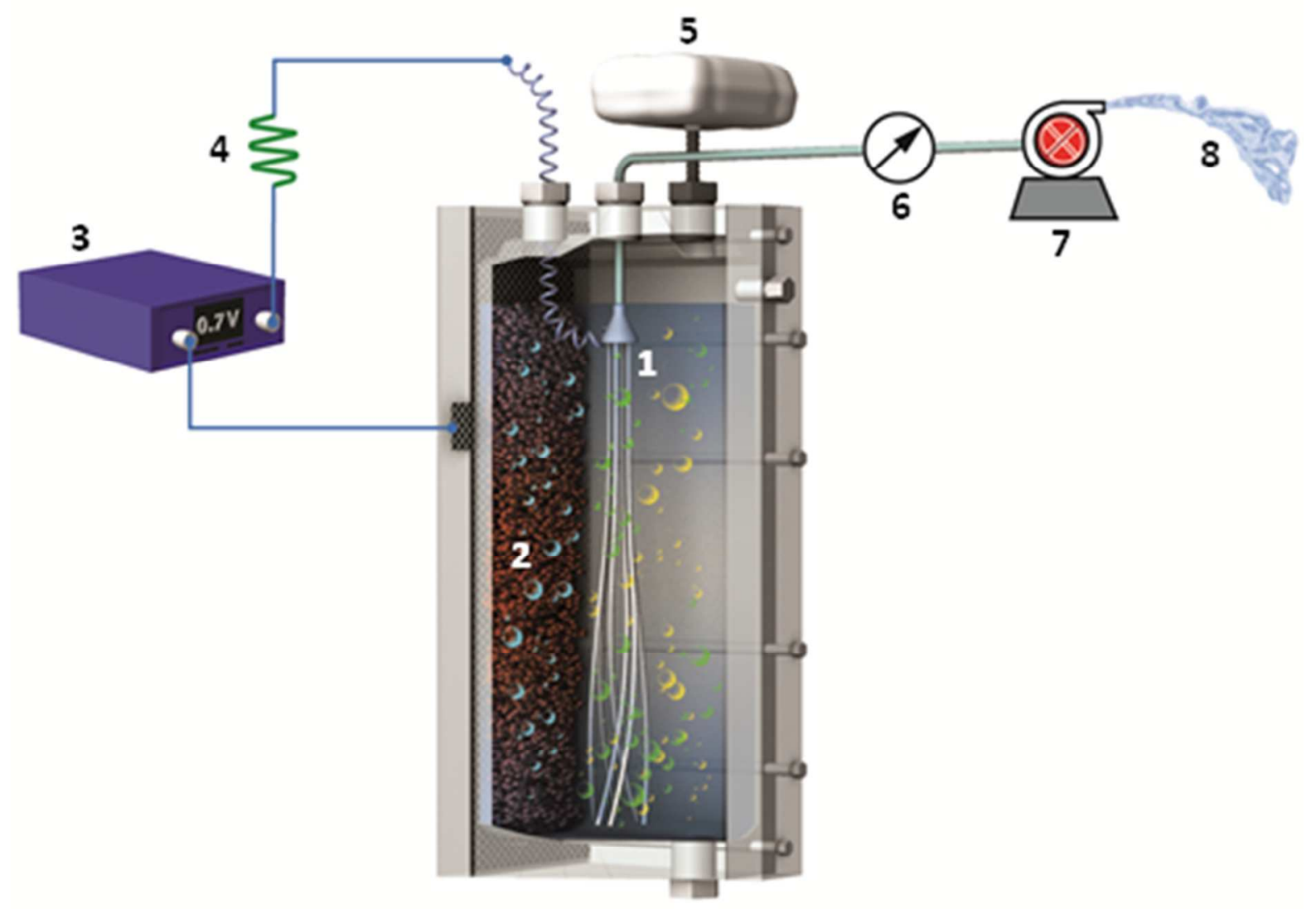

590

$591 \quad$ Figure 1

592 

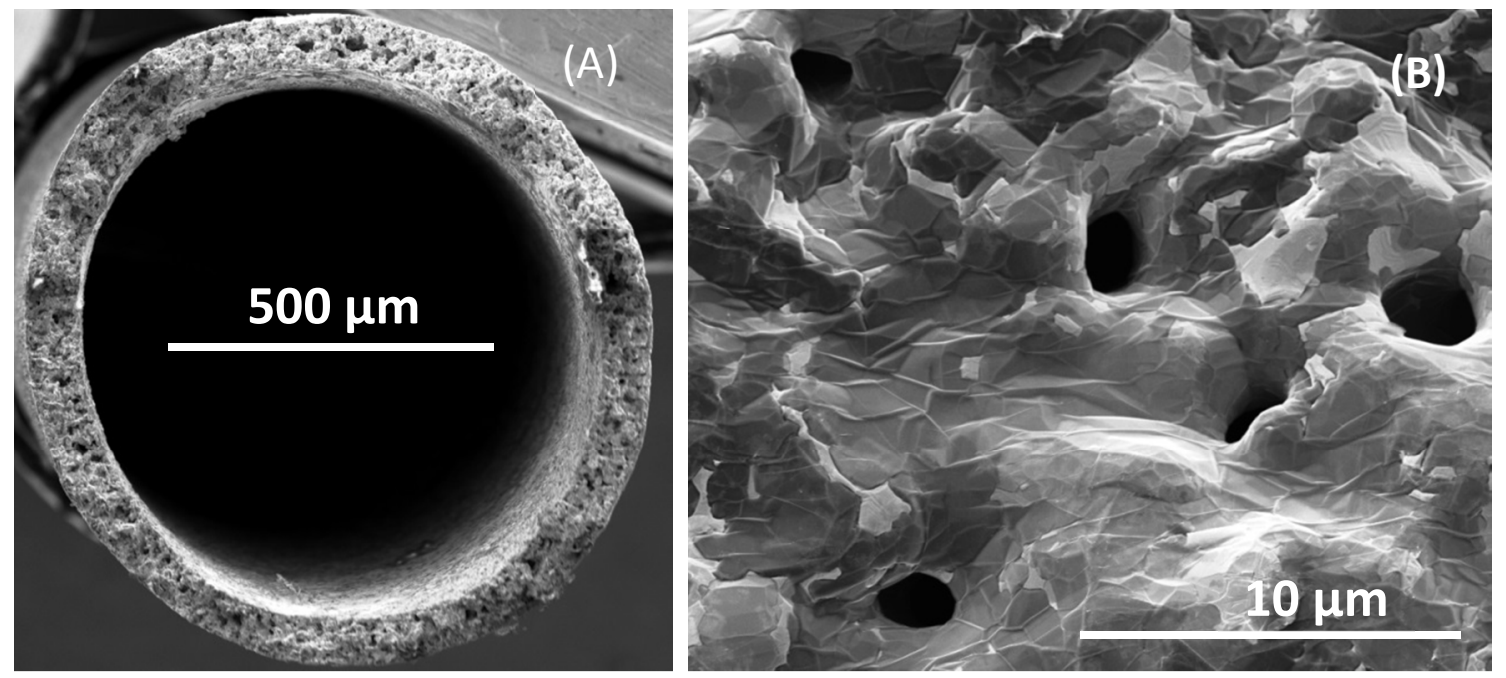

601

602

(C)

603

604

605

606

607

608

609
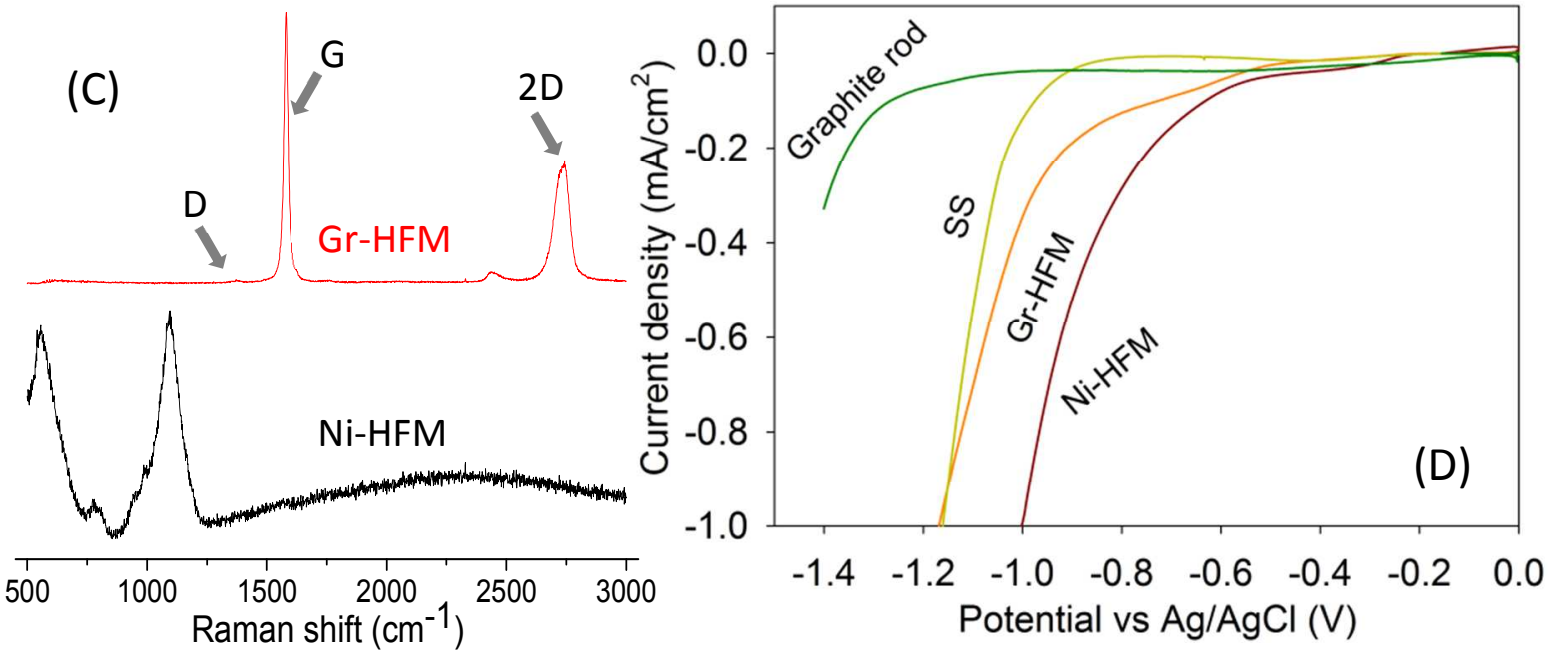

610

611

$612 \quad$ Figure 2 

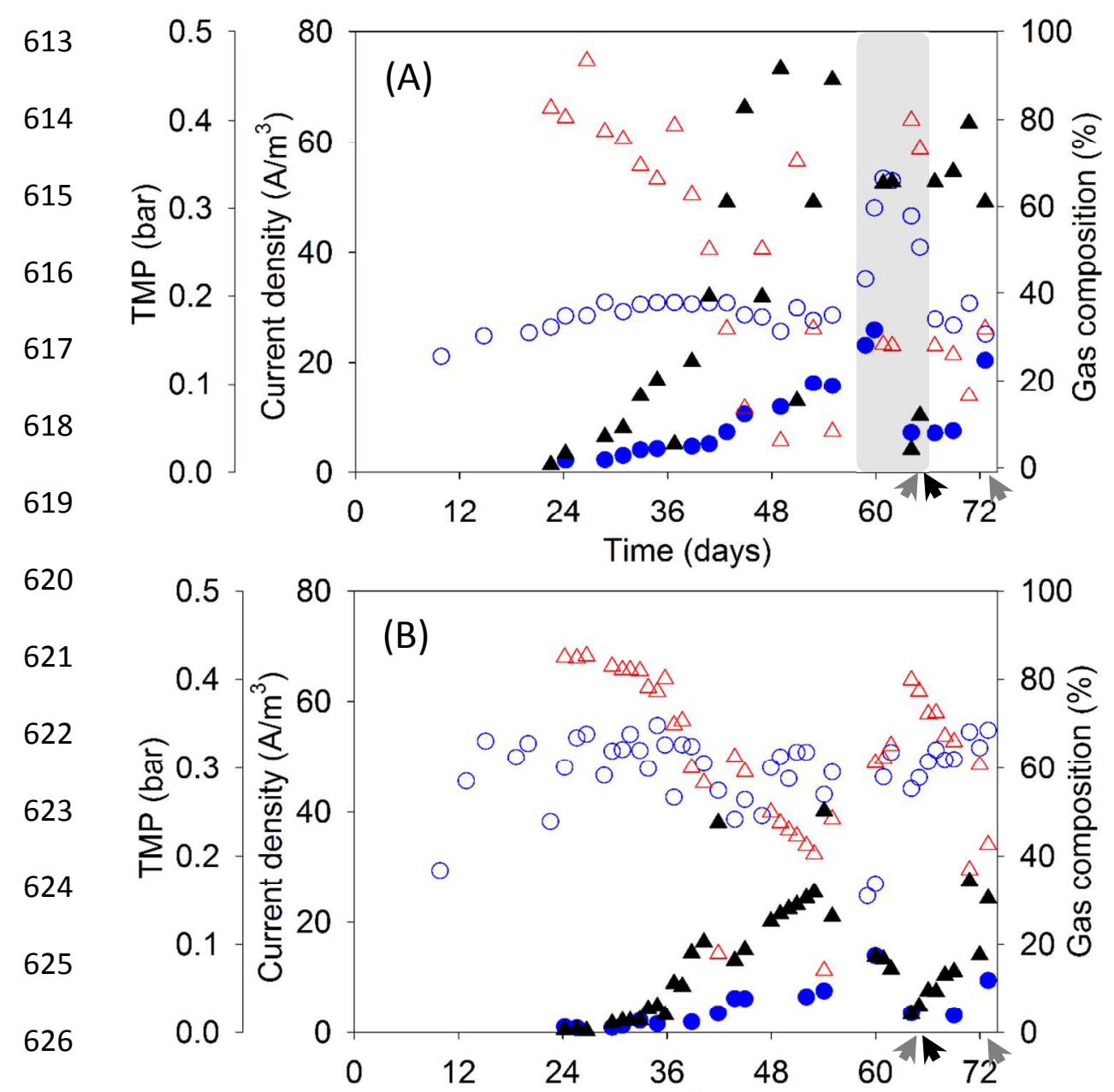

627

628

629

630

631

632

633

634

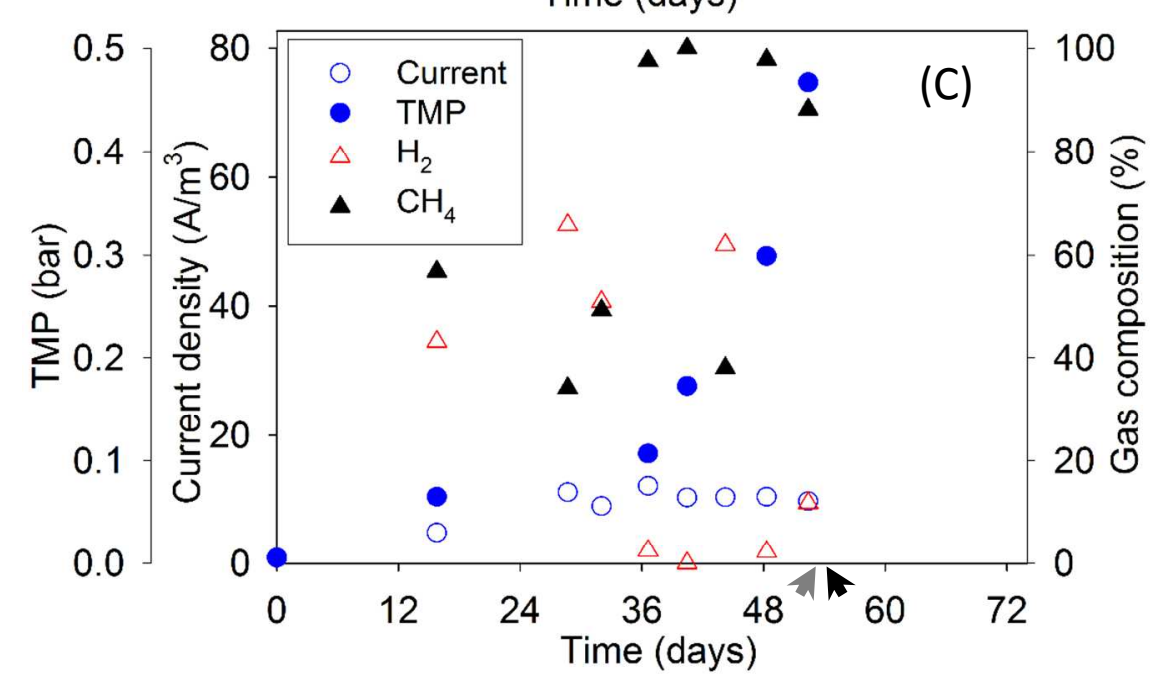

635

636

637 Figure 3 


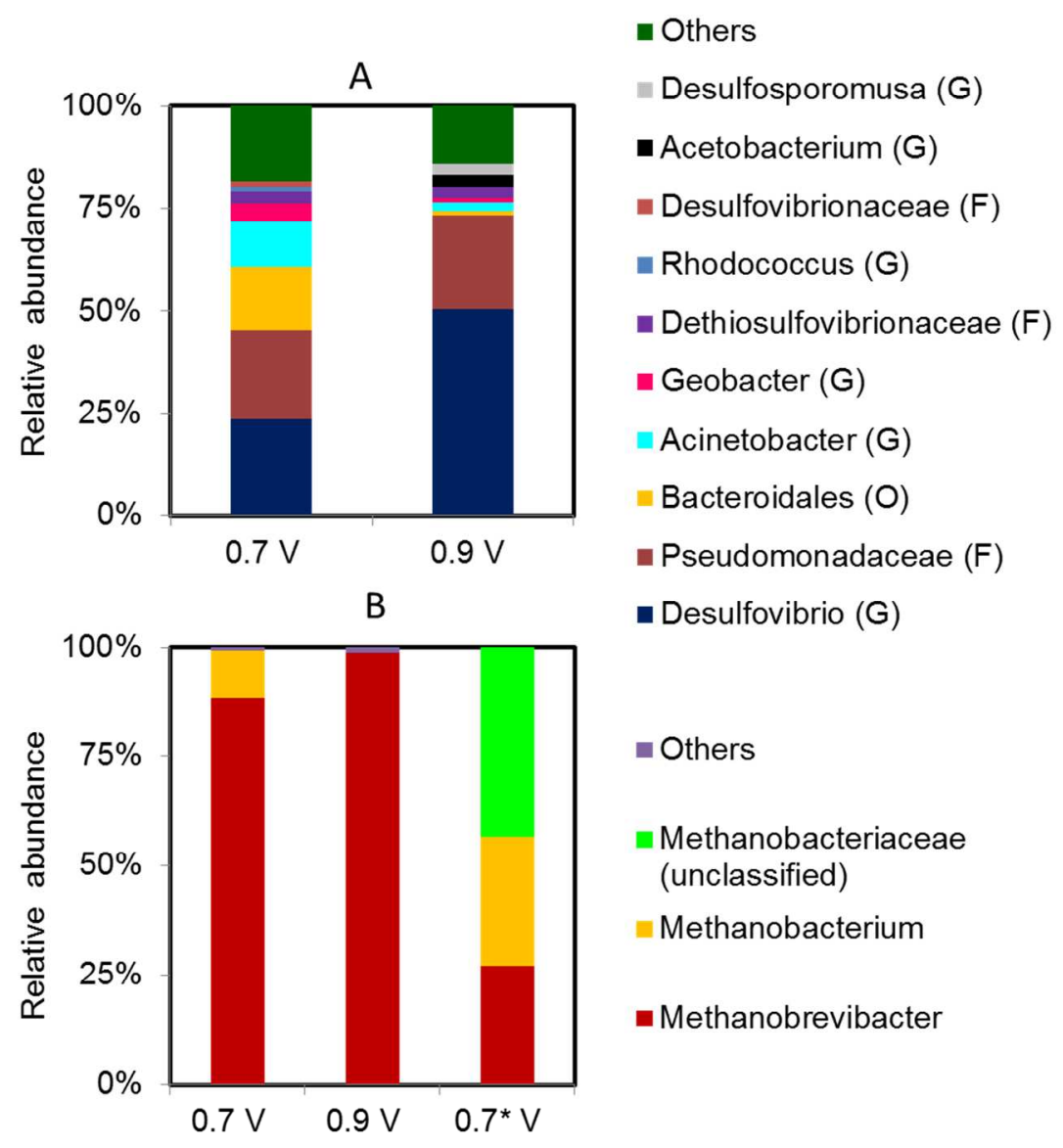

638

639

Figure 4

640

641

642

643

644 


\section{Figure 5}
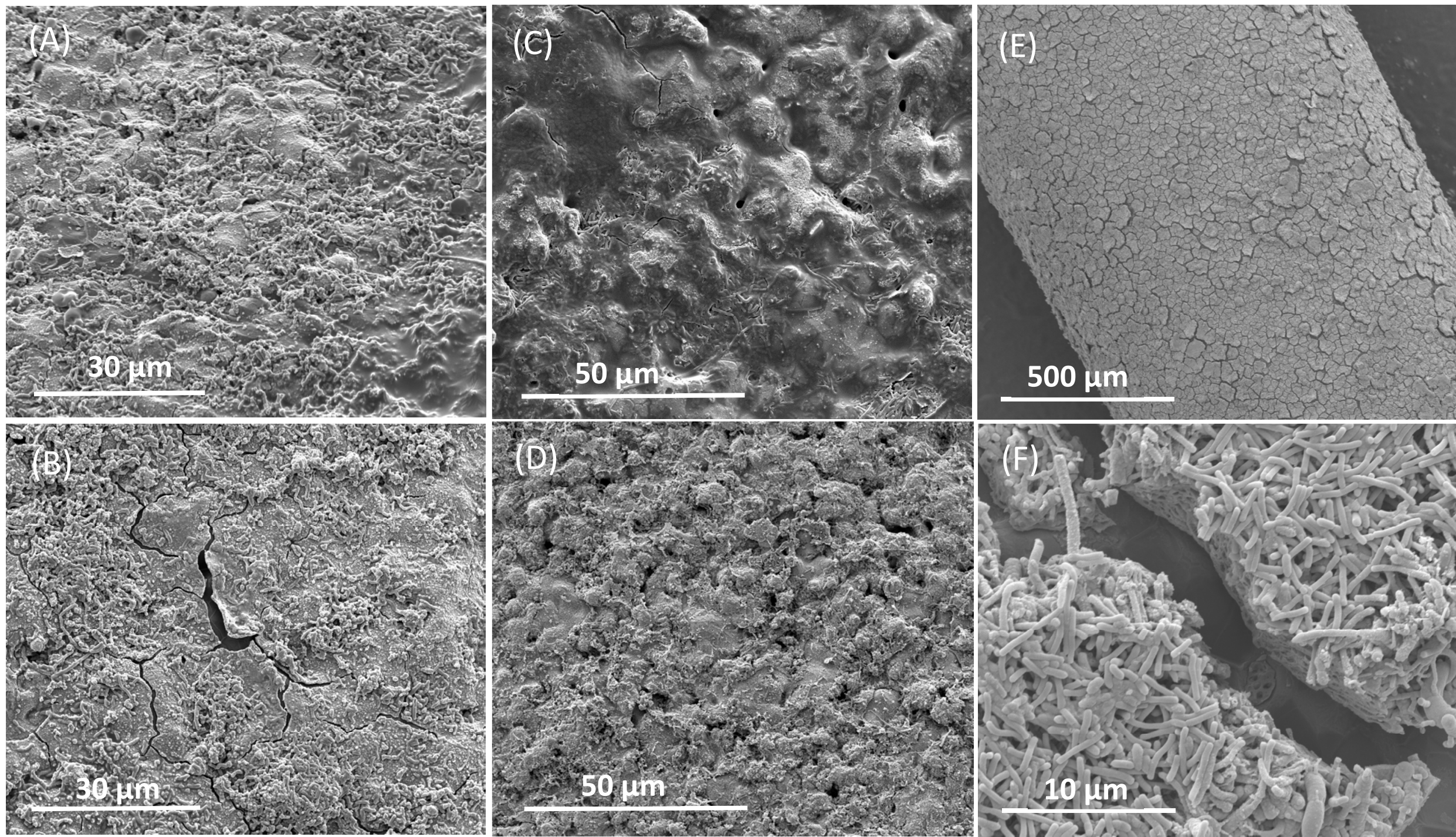
